\title{
Dictyostelium RasD is required for normal phototaxis, but not differentiation
}

\author{
Andrew Wilkins, ${ }^{1,5}$ Meenal Khosla, ${ }^{2,5}$ Derek J. Fraser, ${ }^{3,5}$ George B. Spiegelman, ${ }^{2}$ Paul R. Fisher, ${ }^{3}$ \\ Gerald Weeks, ${ }^{2}$ and Robert H. Insall ${ }^{4,6}$ \\ ${ }^{1}$ MRC Laboratory for Molecular Cell Biology and Departments of Physiology, University College London, London WC1E \\ 6BT, UK; ${ }^{2}$ Department of Microbiology and Immunology and Department of Medical Genetics, University of British \\ Columbia, Vancouver V6T 1Z3, Canada; ${ }^{3}$ Department of Microbiology, La Trobe University, Bundoora, Victoria 3083, \\ Australia; ${ }^{4}$ School of Biosciences, Birmingham University, Edgbaston, Birmingham B15 2TT, UK
}

RasD, a Dictyostelium homolog of mammalian Ras, is maximally expressed during the multicellular stage of development. Normal Dictyostelium aggregates are phototactic and thermotactic, moving towards sources of light and heat with great sensitivity. We show that disruption of the gene for ras $D$ causes a near-total loss of phototaxis and thermotaxis in mutant aggregates, without obvious effects on undirected movement. Previous experiments had suggested important roles for RasD in development and cell-type determination. Surprisingly, ras $D^{-}$cells show no obvious changes in these processes. These cells represent a novel class of phototaxis mutant, and indicate a role for a Ras pathway in the connections between stimuli and coordinated cell movement.

[Key Words: Phototaxis; Dictyostelium; oncogenes; Ras; small GTPases]

Received January 10, 2000; revised version accepted April 7, 2000.

Members of the Ras family of small GTPases are central to a wide range of biological processes, including growth control, signaling, differentiation, and cell motility (Sorcher et al. 1993; Valencia and Sander 1995). Mammalian Ras proteins were discovered originally in an activated form as the products of oncogenes from tumor-promoting viruses (Shih et al. 1979). Expression of a ras gene with an activating mutation is sufficient to transform fibroblast cell lines, resulting in invasive, malignant cells. Microinjection of an activated Ras protein has been shown to cause many of the features of the transformed phenotype, including mitogenesis, altered cell morphology, and membrane ruffling (Bourne et al. 1990). Ras has since been shown to mediate the response to receptor tyrosine kinase activation in several different species, including mammals, Drosophila and C. elegans (Mulcahy et al. 1985; Han and Sternberg 1990; Fortini et al. 1992). In Saccharomyces, Ras proteins are required for control of adenylyl cyclase and for progression through the G1-phase of the cell cycle (Toda et al. 1985).

Dictyostelium contains an unexpectedly large number of Ras subfamily proteins (Reymond et al. 1984; Robbins et al. 1989; Daniel et al. 1993, 1994). Two of these proteins, RasG and RasD, are closely related to mammalian Ha-Ras. The rasG gene is expressed at high levels in growing cells, whereas rasD is expressed at only low lev-

\footnotetext{
${ }^{5}$ These authors contributed equally to this manuscript. ${ }^{6}$ Corresponding author.

E-MAIL R.H.Insall@bham.ac.uk; FAX (44) 1214143982.
}

els during growth, but is induced after the cells initiate multicellular development (Reymond et al. 1984; Khosla et al. 1990; Esch and Firtel 1991). Null mutants containing a disrupted rasG gene exhibit several defects connected with motility, in particular a marked reduction in cell polarity, impaired cytokinesis in suspension, and slow growth (Tuxworth et al. 1997). Cells expressing an activated rasG fail to initiate development unless provided with exogenous cAMP pulses (Khosla et al. 1996). RasG therefore resembles Ras from higher eukaryotes in that it appears to control differentiation, cytoskeletal function, and cell division.

Several experiments have suggested a role for RasD in the correct proportioning of the presumptive stalk and spore (prestalk and prespore) cells during differentiation (Reymond et al. 1986; Louis et al. 1997). The rasD gene is expressed at higher levels in prestalk than prespore cells, suggesting a possible role in prestalk cell differentiation (Jermyn et al. 1987). Furthermore, cells that have been transfected with a rasD gene containing an activating mutation, $r a s D^{G 12 T}$, arrest development after forming multitipped mounds (Reymond et al. 1986). These mutants express enhanced levels of the prestalk cell-specific genes ecm $A$ and $\operatorname{tag} B$, and very low levels of the prespore cell specific gene $\cot C$, suggesting that RasD is involved in the choice of the prestalk cell fate (Louis et al. 1997).

Another Ras pathway member, the presumptive Ras guanine nucleotide exchange factor (RasGEF) encoded by the aimless gene, is required for both cAMP production 
and chemotaxis (Insall et al. 1996). We initially made mutants containing disruptions of different ras genes in an attempt to reproduce the aimless phenotype as part of a search for targets of the Aimless protein. As we describe here, disruption of the ras $D$ gene does not result in any obvious defect in differentiation or a similar phenotype to aimless. Instead, ras $D^{-}$cells develop successfully, producing culminants morphologically indistinguishable from the parental strain. However, rasD ${ }^{-}$slugs show impaired phototactic and thermotactic accuracy, while both processes are normal in ras $G^{-}$slugs. That ras $D^{-}$cells should exhibit such a subtle but definitive phenotype is highly unexpected and suggests a specific role for a RasD signaling pathway in photosensory and thermosensory responses in Dictyostelium.

\section{Results}

Disruption of the Dictyostelium rasD gene

Cells containing a disrupted rasD gene were generated by homologus recombination. A construct was made containing $2.0 \mathrm{~kb}$ of rasD genomic DNA (Reymond et al. 1986), with a blasticidin resistance cassette (Sutoh 1993) inserted into the $5^{\prime}$ end of the ras $D$-coding sequence in the same orientation, so that its strong act 8 termination sequence blocked any transcriptional readthrough. The construct was transfected into AX3 cells, and transformants were cloned following seven days of selection in blasticidin S. Out of seven independent clones examined, six were found to contain a simple disruption in rasD. All clones were indistinguishable in growth and colony morphology and one, designated $\mathrm{rasD}^{-}$, was used for all subsequent work. The wild-type ras $D$ gene was transfected into this clone, using a G418 resistance cassette, as a control for nonspecific effects of transformation. This cell line will be referred to as ras ${ }^{-r a s D}$.

To confirm complete loss of RasD protein, an antibody against RasD was prepared using the approach used previously to generate a specific antibody to RasG (Khosla et al. 1994). Western blot analysis of bacterially expressed Dictyostelium Ras-GST fusion proteins (data not shown) revealed that the antibody exhibited the highest activity against the RasD protein, but still had residual activity against $\mathrm{RasG}$, the closest cellular homolog of RasD, despite extensive cross absorption. Nonetheless, the antibody was sufficiently specific to allow determination of RasD levels.

Western blot analysis of extracts from AX3 cells at various stages of development using the RasD antibody detected two proteins of slightly different mobility, each with a different expression pattern (Fig. 1A). Because the higher mobility band showed the same expression profile as rasD mRNA, it was concluded that this represents the RasD protein. This band was completely absent throughout the development of rasD ${ }^{-}$cells (Fig. 1B). In light of the cross reactivity of the antibody with RasG, the blot was stripped and reprobed with the highly specific RasG antibody. This clearly identified the source of the lower mobility band as RasG (Fig. 1C). Reintroduction of a ge-

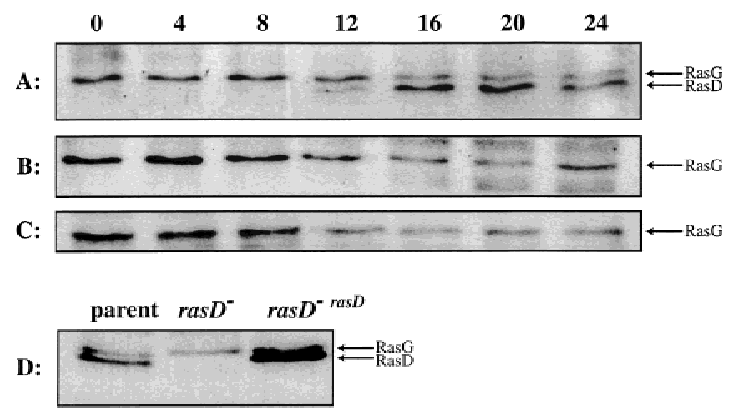

Figure 1. Expression of RasD and RasG proteins during Dictyostelium development. Cells were developed for the indicated times (in hours) then lysed in sample buffer. Twenty $\mu \mathrm{g}$ of total protein was separated by SDS-PAGE, transferred to nitrocellulose, and immunoblotted as described in Materials and Methods. (A) Parental cells probed with anti-RasD; $(B)$ rasD $^{-}$cells probed with anti-RasD; $(C)$ Parental cells probed with antiRasG; $(D)$ Parental, ras $D^{-}$and ras $D^{-}$rescued with genomic ras $D$, all after 14 hrs of development, probed with anti-RasD.

nomic ras $D$ fragment into ras $D^{-}$cells restored the lower band (Fig. 1D).

In experiments using purified proteins, we have found that the RasD antibody shows much more activity towards RasD than RasG ( fivefold; data not shown). The strength of the lower-mobility bands in blots from wildtype cells therefore indicates that cells always contain at least as much RasG as RasD, even late in development when RasD levels are at their peak.

\section{Development of $\mathrm{rasD}^{-}$cells}

Deletion of the rasD gene caused no obvious changes in cell growth or proliferation. Unexpectedly, it also caused no discernible alterations in development-all developmental stages from aggregation through to culmination were seen at the usual times. It has been shown recently that the overexpression of an activated rasD gene leads to a marked increase in prestalk cell-specific gene expression and a decrease in the expression of prespore cell-specific genes during development relative to wild type (Louis et al. 1997). We therefore investigated the expression of several cell-type specific genes during the development of ras $D^{-}$cells to determine if loss of ras $D$ had an effect on cell-type patterning. Accordingly, the same Northern blot was cut and simultaneously probed for the prestalk-specific genes ecm $A$ and ecmB and the prespore-specific gene $p s p A$ (Fig. 2). The blot was stripped and reprobed with the IG7 probe as a control for loading. Unexpectedly, there was no obvious difference in the timing or level of expression of any of the three genes during development of ras $D^{-}$cells. This result is dramatically different from the gross changes seen in cells expressing an activated rasD gene, and indicates that RasD is not required for normal proportioning of prestalk and prespore cells in the developing aggregate. Similarly, the expression of the spiA gene, which is a marker for terminal differentiation of spore cells, is indistinguishable in wild-type and ras $D^{-}$cells (data not shown). 


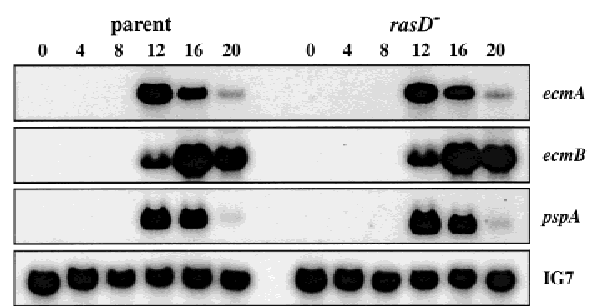

Figure 2. Expression of cell type-specific mRNA during development. Parental and ras $D^{-}$cells were harvested at the indicated times of development (in hours) and total RNA was prepared. Twenty $\mu \mathrm{g}$ of RNA was separated on an agarose gel and transferred to nitrocellulose. The filter was cut into strips and hybridized simultaneously with ecm $A, e c m B, p s p A$, and IG7 (loading control) probes.

\section{Normal pattern formation in $\mathrm{rasD}^{-}$aggregates}

Previous work had implicated RasD in pattern formation during development (Esch and Firtel 1991), in particular in the spatial regulation of gene expression. To test this hypothesis, both rasD ${ }^{-}$cells and the parental strain were transfected with lac $Z$ reporter constructs under the control of different prestalk- and prespore-specific promoters. Cells were allowed to develop to either the slug or preculminant stage, then histochemically stained for $\beta$-galactosidase activity. The prestalk-specific ecmAO promoter (Early et al. 1993) drives expression of lacZ in the anterior fifth of the slug and the basal disc, stalk, tip, and upper and lower cups of the culminant. The ecmO region of the ecmAO promoter causes expression in the rear portion of the tip of the slug. The ecmB promoter is expressed in a cone of cells in the tip of the slug, and in the culminant shows a similar expression pattern to ecm $A$ except that there is no staining of the tip/papilla outside the stalk tube. The prespore specific promoter $p s p A$ is active in the posterior four-fifths of the slug and in the spore mass of the culminant. For each of these reporter constructs, patterning in $\mathrm{ras}^{-}$aggregates was not appreciably different from that of parental strain (Fig. 3).

One powerful way of identifying otherwise hidden developmental defects is to mix cells of the mutant and parental strains to produce chimaeric aggregates, and observe whether the two cell types behave differently. Accordingly, rasD ${ }^{-}$cells constitutively expressing lacZ from the act 15 promoter were mixed with either ras $D^{-}$ cells or the parental strain in a 1:4 ratio. Again, cells were developed to either the slug or preculminant stage, then stained for $\beta$-galactosidase activity. In both mixtures, blue staining could be seen distributed randomly throughout the slugs and preculminants, suggesting that the development of ras $D^{-}$cells is as robust as the parental strain (Fig. 3O-R). Identical staining patterns were also obtained when these experiments were repeated with act15/lacZ expressing AX2 cells instead of rasD cells (data not shown).

\section{Impaired phototaxis and thermotaxis in rasD aggregates}

We did, however, see an obvious defect in phototaxis and thermotaxis in slugs from ras $D^{-}$null cells. Dictyostelium discoideum cells form motile slugs after aggregation. These seek out optimal conditions for culmination, using phototaxis and thermotaxis, in which the slugs move with great sensitivity towards sources of light (Fisher and Williams 1981) and heat (Smith et al. 1982). When slugs from wild-type cells are kept in the presence of lateral light, they move almost directly towards the light source (Fig. 4). The ras $D^{-}$slugs were obviously less able to orient correctly (Fig. 4). To verify that this phenotype was caused by loss of RasD, and not an incidental consequence of transformation or selection, the ras $D^{-}$ null cells were retransformed with a genomic copy of rasD. Several different transformants were examined, all of which exhibited normal phototaxis (Fig. 4B). We also examined strains in which rasD had been disrupted with different selectable markers; again, loss of RasD caused defective phototaxis in every case (data not shown).

Figure 5 shows quantitative measurements of phototaxis and thermotaxis (Fisher et al. 1981). Data were analyzed using the von Mises distribution, which yields a quantitative parameter $\kappa$ describing the accuracy of ori-

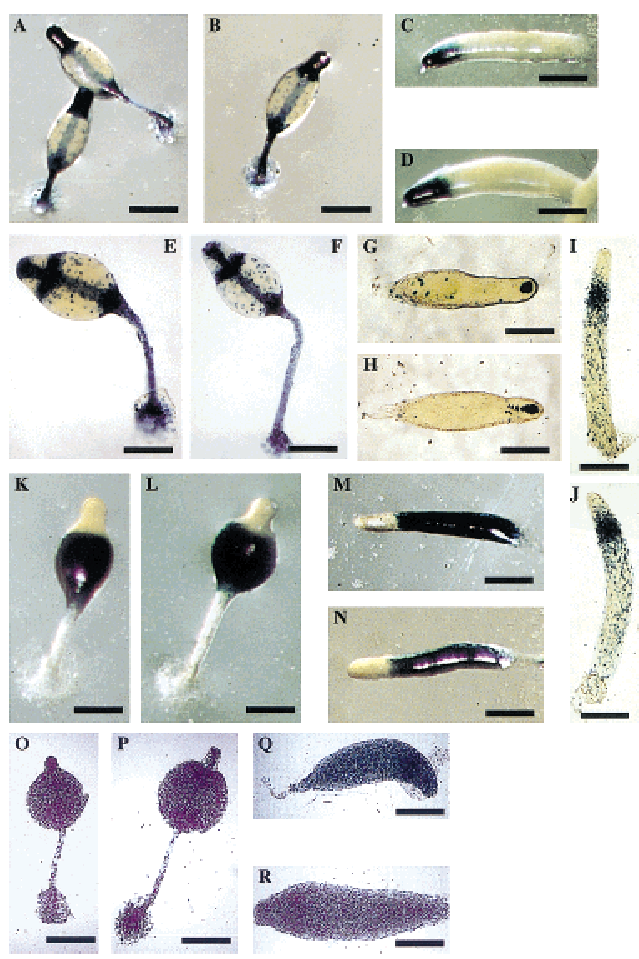

Figure 3. Spatial expression of cell type-specific lacZ reporter constructs during development. ras $D^{-}$and parental cells were transformed with various lacZ reporter constructs, developed on KK2 agar to either the slug ( $15 \mathrm{hr}$ ) or early culminant ( $18 \mathrm{hr}$ ) stage, and fixed and stained as described in Materials and Methods. EcmAO-lacZ marker in parental $(A, C)$ and $\operatorname{ras}^{-}(B, D)$ aggregates; ecmB-lacZ marker in parental $(E, F)$ and $\operatorname{ras}^{-}(G, H)$ culminants; ecmO-lacZ marker in parental $(I)$ and $\operatorname{rasD}^{-}(J)$ first fingers; pspA-lac $Z$ marker in parental $(K, L)$ and $\operatorname{rasD}^{-}(M, N)$ aggregates; 50:50 mixes of actin15-1acZ marker in ras $D^{-}$cells with unlabeled parental $(O, P)$ or $\operatorname{ras}^{-}(Q, R)$ cells. 
A

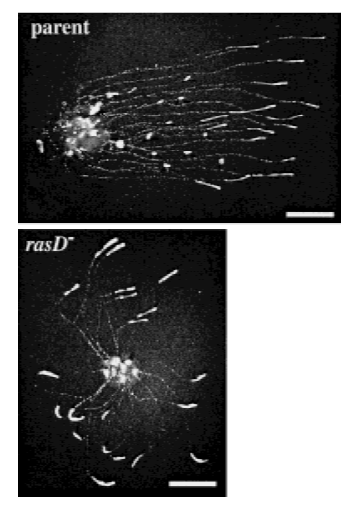

B

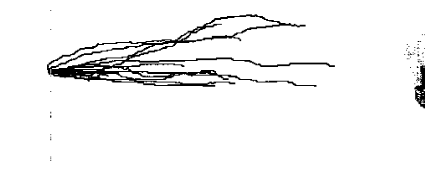

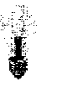
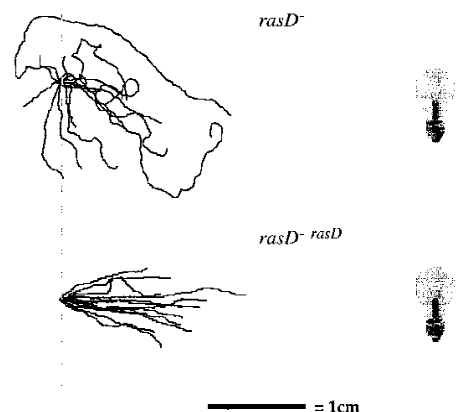

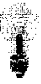

Figure 4. Phototaxis of wild-type and $\mathrm{ras}^{-}$cells. (A) Wildtype and ras $D^{-}$cells were inoculated onto charcoal agar plates, incubated for $48 \mathrm{hr}$ in the presence of a lateral light source, and the resultant slug trails photographed. (B) Wild-type, rasD ${ }^{-}$and ras $D^{-r a s D}$ cells were inoculated onto charcoal agar plates, incubated for $48 \mathrm{hr}$ in the presence of a lateral light source, and the resultant slug trails were transferred to PVC disks, stained with Coomassie Blue, and digitized. The light source was towards the right of the figure in each case.

entation. A $\kappa$ of zero reflects no phototaxis and infinity indicates perfect orientation along the gradient. For the parental strain, $\kappa$ varied from 100-500 (Fig. 5A). The ras $D^{-}$slugs were substantially less phototactic, although a slight positive response was measured, with a $\kappa$ of 5-10 (Fig. 5A, inset). As reported in Fisher et al. (1981), the initial cell density has a marked effect on the efficiency of phototaxis, so measurements were made at a range of densities. The ras $D^{-}$slugs were clearly defective at all densities tested. Other reported mutants, such as those lacking the actin-binding protein ABP-120 (Fisher et al. 1997), can be even more severely impaired with accuracies of phototaxis $(\kappa)$ as low as $0.5-1.0$. Again, rasD ${ }^{-}$ slugs which had been rescued with genomic ras $D$ exhibited similar phototaxis to the wild type. As a control for nonspecific effects caused by alteration of Ras levels,

slugs containing a deletion in the related $\operatorname{ras} G$ gene were examined. These again showed wild-type phototaxis (data not shown).

Cells lacking the rasD gene also exhibit impaired thermotaxis (Fig. 5B), in common with several other phototaxis mutants. Thermotaxis by the ras $D^{-}$mutant was almost undetectable, while the ras $D^{-r a s D}$ rescue strains and the ras $G^{-}$strain again behaved in a similar way to the parent.

\section{Discussion}

We have successfully generated a Dictyostelium cell line with a disrupted rasD gene. Unexpectedly, in the light of reports that RasD was important for differentiation (Reymond et al. 1986) and cell type determination (Esch et al. 1992; Louis et al. 1997), the disruptants grow, aggregate, and develop indistinguishably from the wild type. This contrasts sharply with the strong phenotypes caused by loss of RasG (Tuxworth et al. 1997) and RasS (Chubb et al. 2000).

Previous reports have shown that expression of a RasD protein containing an activating mutation (G12T) has a profound effect on development. Although cells aggregated normally, the mounds that formed were multitipped and unable to develop further (Reymond et al. 1986). In addition, pattern formation was markedly disrupted, with prestalk gene expression greatly enhanced and prespore gene expression greatly reduced (Louis et al. 1997). There are several plausible explanations for this phenomenon.

First, RasD might play one or more major roles in wild-type development. Its loss could, for the most part, be compensated for by the modulated activity of other Ras proteins in the cell. Indeed, there are at least three other Ras proteins present in the cell during multicellular development: RasB, RasC, and RasG (Reymond et al. 1984; Robbins et al. 1989; Daniel et al. 1993, 1994). RasG would be a particularly suitable suitable candidate, sharing $100 \%$ identity in the effector and effector-proximal domains, and $82 \%$ identity over its entire length, and al-
Figure 5. Accuracy of phototaxis and thermotaxis. $(A)$ Variation of phototactic efficiency with initial cell density. Parent $(\square)$, rasD null $(\triangle)$, ras $G$ null $(O)$, and rasD null rescued with a genomic rasD construct (ם) were plated at different densities, and slug trails were observed as in Figure 2. Data were digitized and analyzed according to Fisher et al. (1981). The inset panel shows the rasD null data plotted on a narrower scale to show slight phototaxis. $(B)$ Variation of thermotactic efficiency with mean temperature. Cells were inoculated at $2.4 \times 10^{6}$ cells $/ \mathrm{cm}^{2}$ onto water agarose plates and incubated in the presence of a lateral light source $(A)$ or in darkness on a heat bar producing $0.2^{\circ} \mathrm{C} / \mathrm{cm}$ temperature gradient at the agarose surface $(B)$. Arbitrary temperature units correspond to a temperature range of $14^{\circ} \mathrm{C}$ (T1) to $28^{\circ} \mathrm{C}$ (T8), as measured at the center of the plates in separate calibration experiments.
A

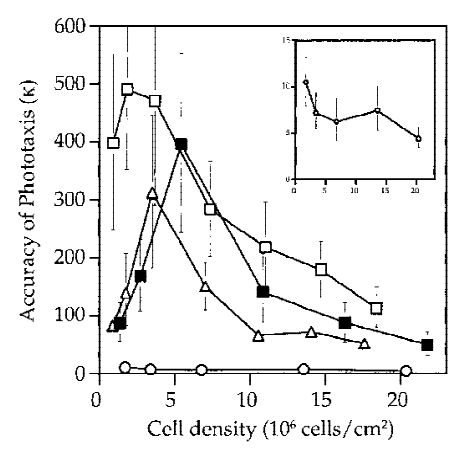

B

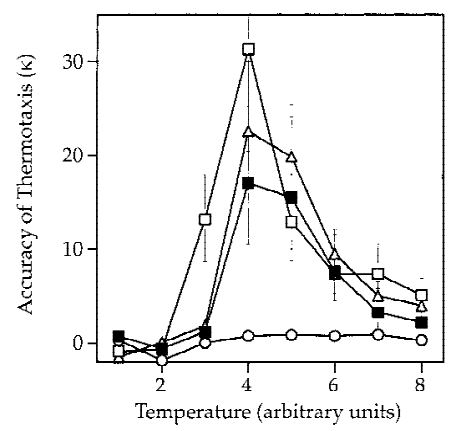


though rasG mRNA levels decline early in development (Khosla et al. 1990), a substantial quantity of protein is present throughout development (see Fig. 1).

Alternatively, the role of RasD might be limited to the signal transduction pathways common to phototaxis and thermotaxis in the slug stage. In this case, the profound effects of activated RasD expression could be due to interference with a pathway that is normally controlled by a different Ras protein. Previous genetic studies on slug phototaxis (Darcy et al. 1994) have suggested that there are about 20 genes involved in slug phototaxis (that is, mutations in about 20 genes cause loss of phototaxis but allow the formation of otherwise normal slugs). This suggests the existence of a fairly complex signaling system. In the current model of phototaxis, light and temperature gradients modulate the slug tip activation/inhibition system to cause slug turning by stimulating lateral shifts in tip position (Darcy et al. 1994; Fisher 1997). Accordingly, many phototaxis mutants exhibit one of two developmental abnormalities: They either form multiply-tipped culminants with few or no spores, or they form stumpy fruiting bodies with little or no stalk (Darcy et al. 1994). These phenotypes are consistent with impairment of tip inhibition and activation pathways, respectively.

In the case of RasD, continuous high activity of the protein causes the multiple-tip phenotype (Reymond et al. 1986; Esch et al. 1992; Louis et al. 1997), whereas its complete absence causes impaired phototaxis and thermotaxis without any noticeable developmental defects (Wilkins et al., this issue). Together, these findings suggest that the RasD protein, when activated, stimulates the tip activation signaling pathway, but that this activity is normally only induced in response to light and temperature gradients. Thus, the role of RasD in slugs may not be in morphogenetic signaling per se, but in the modulation of morphogenetic signaling by the photoand thermo-receptors. This highlights the danger that high-level expression of a constitutively active Ras protein can affect processes not normally controlled by it. The point is particularly relevant in the light of the small amounts of RasD protein found at any stage in development when compared with RasG (Fig. 1; below).

Previous work has implicated Ras in other types of directed cell migration during the development of Dictyostelium, C. elegans, and Drosophila. However, to our knowledge this is the first report of a role for a Ras protein in either phototaxis or thermotaxis. It will be extremely interesting to see whether a similar pathway exists in any other species.

\section{Materials and methods}

Unless otherwise indicated, all chemicals were obtained from Sigma Chemical Company and all restriction enzymes from New England Biolabs.

Cell strains, growth, and transformation

Dictyostelium discoideum AX3 cells were either grown axenically in HL5 medium or on a bacterial food source at $22^{\circ} \mathrm{C}$
(Sussman and Sussman 1967). For bacterially grown cells, SM agar plates were inoculated with $10^{5}-10^{6}$ Dictyostelium cells plus a suspension of Klebsiella aerogenes in Luria broth. To follow differentiation, cells growing exponentially from bacterial plates or axenic growth media were washed three times in $\mathrm{KK} 2$ (16.5 $\mathrm{mM} \mathrm{KH}_{2} \mathrm{PO}_{4}, 3.8 \mathrm{~mm} \mathrm{~K}_{2} \mathrm{HPO}_{4}$ at $\left.\mathrm{pH} 6.0\right)$ and plated on KK2 agar or nitrocellulose filters (Millipore).

Transformation was performed by a modification of Howard et al. (1988); briefly, cells growing exponentially were mixed with $25 \mu \mathrm{g}$ of linearized DNA and electroporated in a BioRad gene pulser at 1.0 or $1.1 \mathrm{~V}, 3 \mu \mathrm{F}$ with a 5 -ohm resistance in series. After $10 \mathrm{~min}$ incubation on ice, cells were placed at $22^{\circ} \mathrm{C}$ for $15^{\prime}$ in the presence of $2 \mu$ l healing solution $\left(100 \mathrm{mM} \mathrm{MgCl}_{2}, 100 \mathrm{~mm}\right.$ $\mathrm{CaCl}_{2}$ ) and then HL-5 added. Ten $\mu \mathrm{g} / \mathrm{ml}$ Blasticidin-S (ICN) or G418 (Calbiochem) was added $24 \mathrm{hr}$ after electroporation. After 7-8 days antibiotic selection, transformants were cloned on lawns of Klebsiella growing on SM agar. For uracil auxotrophic selection, DH1 cells were used, and FM medium (Franke and Kessin 1977) was added in place of HL-5.

ecmAO/lacZ, ecmB/lacZ, ecmO/lacZ, pspA/lacZ, and act $15 / 1 a c Z$ strains were generated by $\mathrm{CaPO}_{4}$ transfection of both $\mathrm{rasD}^{-}$cells and the parental strain (Harwood et al. 1992). Initial transformants were selected at $50 \mu \mathrm{g} / \mathrm{ml}$ G418 whereas stable transformants were maintained at $20 \mu \mathrm{g} / \mathrm{ml} \mathrm{G} 418$.

\section{Vector construction and Southern analysis}

The rasD knockout vector was constructed by inserting the Blasticidin resistance gene (bsr) from pBsrobam (Sutoh 1993) into the single PstI site of a 2.0-kb, EcoRI/BcII fragment of rasD genomic DNA (Reymond et al. 1984) cloned into the EcoRI and BamHI sites of pBluescript $\mathrm{KS}^{+}$. The bsr gene was oriented in the same direction as the rasD gene to ensure the presence of a transcriptional terminator in the middle of the ras $D$-coding sequence. From the resulting vector (pATW5) the 3.3-kb rasD/bsr fragment was excised using EcoRI and SpeI and used to transform Dictyostelium strain AX3 as described above. To analyze clones, $\mathrm{AX} 3$ or ras $D^{-}$ genomic DNA, prepared by the method of Sun et al. (1990), was digested with EcoRI and BclI, blotted onto nylon membrane (Amersham), and probed with a $\left[\alpha_{-}{ }^{32} \mathrm{P}\right] \mathrm{dATP}$ labeled ClaI/BclI fragment of rasD genomic DNA (Reymond et al. 1984). The rasD rescue vector was constructed by ligating an $\mathrm{XbaI}$ fragment containing the G418-resistance cassette from pDNeo2 and an XbaI/ $E c o$ RI fragment containing the complete ras $D$ gene (including the endogenous promoter) into pBluescript $\mathrm{KS}^{+}$.

\section{Protein isolation and Western analysis}

To determine Ras protein levels in cell extracts, $\sim 5 \times 10^{7}$ washed cells were lysed by resuspension in $1 \%$ sodium dodecyl sulphate (SDS) and mixed with an equal volume of $2 \times$ sample buffer $0.5 \% \beta$-mercaptoethanol, $0.5 \%$ SDS, $50 \mathrm{~mm}$ Tris at $\mathrm{pH}$ $6.8,12.5 \%$ glycerol, $0.04 \%$ bromophenol blue). The specificity of the RasD antibody was determined against different levels of purified RasD-GST and RasG-GST. Samples were boiled for 3 min and then subjected to SDS-PAGE. The separated proteins were transferred onto nitrocellulose membranes and the antiRasG and anti-RasD specific antibodies were used to detect RasG and RasD, respectively. The blots were blocked with TBS $(50 \mathrm{~mm}$ Tris- $\mathrm{HCl}, 150 \mathrm{~mm} \mathrm{NaCl}$ at $\mathrm{pH} 7.5$ ) containing $0.5 \%$ Tween 20 and $5 \%$ nonfat dry milk for at least $1 \mathrm{hr}$ at room temperature. After filters were washed, they were incubated with the primary antibody $(1: 1000)$ in TBS containing $1 \%$ nonfat dry milk for $1 \mathrm{hr}$ at room temperature. The bound antibody was detected by incubating blots with a secondary conjugated donkey anti-rabbit IgG antibody $(1: 10,000)$ in TBS containing 
$0.5 \%$ nonfat dry milk for $1 \mathrm{hr}$ at room temperature. The bound secondary antibody was detected using enhanced chemiluminescence (ECL, Amersham). Western blots were stripped in 100 $\mathrm{mm} \beta$-mercaptoethanol, $2 \%$ SDS, $62.5 \mathrm{~mm}$ Tris- $\mathrm{HCl} \mathrm{pH} 6.7$ at $50^{\circ} \mathrm{C}$ for $30 \mathrm{~min}$. They were then washed in TBS for $20 \mathrm{~min}$ and incubated with $5 \%$ nonfat dry milk and reprobed as described previously.

\section{Production of anti-RasD antiserum}

GST-RasG protein was produced as described previously (Khosla et al. 1994). GST-RasD protein was generated by the same general procedure except it was bound to glutathione-Sepharose $4 \mathrm{~B}$ beads (Sigma) and then eluted with $15 \mathrm{~mm}$ reduced glutathione. Antibody against RasD was raised by the methodology described previously (Khosla et al. 1994), except that $100 \mu \mathrm{g}$ of purified GST-RasD protein was mixed 1:1 with Titremax (Sigma) prior to intramuscular injection and booster injections of the same amount of protein were given after 14, 28, and 56 days. Serum was collected after 70 days, the IgG fraction was prepared and antibodies directed to the GST portion of the protein were removed as described previously (Khosla et al. 1994). The remaining antibody was bound to GST-RasD-Affigel 10 beads and then eluted with $3.5 \mathrm{M} \mathrm{MgCl}_{2}$. The eluted antibody was dialyzed overnight at $4^{\circ} \mathrm{C}$ against TBS and concentrated in a dialysis bag immersed in PEG 20,000 (BDH). Antibodies that recognized common epitopes to the other Ras subfamily proteins were removed by absorption to GST-RasG-Affigel 10 by the method described previously (Khosla et al. 1994).

\section{Phototaxis and thermotaxis assays}

Qualitative phototaxis tests were performed as described previously (Darcy et al. 1994) by using sterile spatula-style toothpicks to transfer cells to charcoal agar plates from the edges of colonies growing on Klebsiella aerogenes lawns. Phototaxis was scored after $48 \mathrm{hr}$ incubation at $21^{\circ} \mathrm{C}$ with a lateral light source.

For quantitative phototaxis experiments, washed amebae were inoculated onto the centers of charcoal agarose plates $(\mathrm{pH}$ 6.5 ) at various densities and incubated with a lateral light source for $48 \mathrm{hr}$ at $21^{\circ} \mathrm{C}$.

For quantitative thermotaxis experiments, washed amebae were inoculated onto the centers of water agarose plates $\left(\sim 2.4 \times 10^{6}\right.$ cells $\left./ \mathrm{cm}^{2}\right)$ and incubated for $72 \mathrm{hr}$ in darkness on a heat bar producing a $0.2^{\circ} \mathrm{C} / \mathrm{cm}$ temperature gradient at the agarose surface. Arbitrary temperature units correspond to a temperature range of $14^{\circ} \mathrm{C}(\mathrm{T} 1)$ to $28^{\circ} \mathrm{C}(\mathrm{T} 8)$, as measured at the center of plates in separate calibration experiments.

Slug trails were transferred to PVC disks, stained with Coomassie Blue, and digitized. Slug orientation was analyzed using directional statistics (Fisher et al. 1981).

\section{RNA isolation and Northern analysis}

Total RNA was extracted using phenol/SDS (Berks and Kay 1990). RNA (20 $\mu \mathrm{g})$, resuspended in $50 \%$ formamide, $40 \mathrm{~mm}$ 3-(N-morpholino) propanesulfonic acid ( $\mathrm{pH} 7.0), 10 \mathrm{~mm}$ sodium acetate, $1 \mathrm{~mm}$ EDTA, 6\% formaldehyde, was size-fractionated on $1.25 \%$ formaldehyde-agarose gels and transferred onto nitrocellulose membranes. Specific cDNAs encoding various genes were radiolabeled by the random primer method using $\left[\alpha-{ }^{32} \mathrm{P}\right] \mathrm{dATP}$ (Amersham). The prehybridization and hybridization conditions of the nitrocellulose filters have been described previously. After hybridization, the filters were washed first with $2 \times$ SSC, $0.1 \%$ SDS at room temperature, then with $0.5 \times$ SSC, $0.1 \%$ SDS at $60^{\circ} \mathrm{C}$ and exposed to X-ray film. After being hybridized by the first cDNA probe, blots were stripped with $0.1 \times$ SSC, $0.1 \%$ SDS, $25 \%$ formamide at $65^{\circ} \mathrm{C}$ and then rehybridized with a second cDNA probe.

\section{Histochemical staining for $\beta$-galactosidase activity}

Aggregates and slugs were fixed for $15 \mathrm{~min}$ in $1 \%$ glutaraldehyde in Z-buffer $\left(60 \mathrm{~mm} \mathrm{NaH}_{2} \mathrm{PO}_{4}, 40 \mathrm{~mm} \mathrm{Na} \mathrm{HPO}_{4}, 10 \mathrm{~mm}\right.$ $\mathrm{KCl}, 1 \mathrm{mM} \mathrm{MgSO}_{4}, 2 \mathrm{mM} \mathrm{MgCl}_{2}$ ). Samples were washed twice in Z-buffer then incubated in staining solution $10.1 \%$ 5-bromo-4chloro-3-indolyl- $\beta$-D-galactoside, $5 \mathrm{~mm}$ potassium ferricyanide, and $5 \mathrm{~mm}$ potassium ferrocyanide in Z-buffer) at $37^{\circ} \mathrm{C}$ (Dingermann et al. 1989|.

\section{Acknowledgments}

We thank Dr. Adrian Harwood (LMCB, University College London) for his support at the end of this project, and for providing several cDNA probes. The work described in this paper was supported by Wellcome Trust Career Development Fellowship 043754 and by a Medical Research Council Senior Fellowship to R.H.I. and by an Australian Research Council grant to P.R.F. We thank Z. Wilczynska for technical assistance. A.W. was supported by the MRC graduate program at the LMCB, University College London.

The publication costs of this article were defrayed in part by payment of page charges. This article must therefore be hereby marked "advertisement" in accordance with 18 USC section 1734 solely to indicate this fact.

\section{References}

Berks, M. and R.R. Kay. 1990. Combinatorial control of cell differentiation by cAMP and DIF-1 during development of Dictyostelium discoideum. Development 110: 977-984.

Bourne, H.R., D.A. Sanders, and F. McCormick. 1990. The GTPase superfamily: A conserved switch for diverse cell functions. Nature 348: 125-132.

Chubb, J.R., A. Wilkins, G. Thomas, and R.H. Insall. 2000. The Dictyostelium RasS protein is required for macropinocytosis, phagocytosis and the control of cell movement. J. Cell Sci. 113: 709-719.

Daniel, J., G.B. Spiegelman, and G. Weeks. 1993. Characterization of a third ras gene, $\operatorname{ras} B$, that is expressed throughout the growth and development of Dictyostelium discoideum. Oncogene 8: 1041-1047.

Daniel, J., J. Bush, J. Cardelli, G.B. Spiegelman, and G. Weeks. 1994. Isolation of two novel ras genes in Dictyostelium discoideum-evidence for a complex, developmentally regulated ras gene subfamily. Oncogene 9: 501-508.

Darcy, P.K., Z. Wilczynska, and P.R. Fisher. 1994. Genetic analysis of Dictyostelium slug phototaxis mutants. Genetics 137: 977-985.

Dingermann, T., N. Reindl, H. Werner, M. Hildebrandt, W. Nellen, A. Harwood, J. Williams, and K. Nerke. 1989. Optimization and in situ detection of Escherichia coli $\beta$-galactosidase gene expression in Dictyostelium discoideum. Gene 85: 353-362.

Early, A.E., M.J. Gaskell, D. Traynor, and J.G. Williams. 1993. Two distinct populations of prestalk cells within the tip of the migratory Dictyostelium slug with differing fates at culmination. Development 118: 353-362.

Esch, R.K. and R.A. Firtel. 1991. cAMP and cell sorting control the spatial expression of a developmentally essential cell- 
type-specific ras gene in Dictyostelium. Genes \& Dev. 5: 921.

Esch, R.K., P.K. Howard, and R.A. Firtel. 1992. Regulation of the Dictyostelium cAMP-induced, prestalk-specific DdrasD gene: Identification of cis-acting elements. Nucleic Acids Res. 20: 1325-1332.

Fisher, F.R., E. Smith, and K.L. Williams. 1981. An extracellular chemical signal controlling phototactic behavior by D. discoideum slugs. Cell 23: 799-807.

Fisher, P.R. 1997. Genetics of phototaxis in a model eukaryote, Dictyostelium discoideum. BioEssays 19: 397-407.

Fisher, P.R. and K.L. Williams. 1981. Bidirectional phototaxis by Dictyostelium discoideum slugs. FEMS Microbiol. Lett. 12: 87-89.

Fisher, P.R., A.A. Noegel, M. Fechheimer, F. Rivero, J. Prassler, and G. Gerisch. 1997. Photosensory and thermosensory responses in Dictyostelium slugs are specifically impaired by absence of the F-actin cross-linking gelation factor (ABP120). Curr. Biol. 7: 889-892.

Fortini, M., M. Simon, and G. Rubin. 1992. Signaling by the sevenless protein tyrosine kinase is mimicked by ras 1 activation. Nature 355: 559-561.

Franke, J. and R. Kessin. 1977. A defined minimal medium for axenic strains of Dictyostelium discoideum. Proc. Natl. Acad. Sci. 74: 2157-2161.

Han, M. and P. Sternberg. 1990. Let-60, a gene which specifies cell fates during vulval induction, encodes a ras protein. Cell 63: 921-931.

Harwood, A.J., N.A. Hopper, M.N. Simon, S. Bouzid, M. Veron, and J.G. Williams. 1992. Multiple roles for cAMP-dependent protein kinase during Dictyostelium development. Dev. Biol. 149: 90-99.

Howard, P.K., K.G. Ahern, and R.A. Firtel. 1988. Establishment of a transient expression system for Dictyostelium discoideum. Nucleic Acids Res. 16: 2613-2623.

Insall, R.H., J. Borleis, and P.N. Devreotes. 1996. The aimless RasGEF is required for processing of chemotactic signals through G-protein-coupled receptors in Dictyostelium. Curr. Biol. 6: 719-729.

Jermyn, K.A., M. Berks, R.R. Kay, and J.G. Williams. 1987. Two distinct classes of prestalk-enriched mRNA sequences in Dictyostelium discoideum. Development 100: 745-755.

Khosla, M., S.M. Robbins, G.B. Spiegelman, and G. Weeks. 1990. Regulation of DdrasG gene expression during Dictyostelium development. Mol. Cell. Biol. 10: 918-922.

Khosla, M., G.B. Spiegelman, G. Weeks, T.W. Sands, K.J. Virdy, and D.A. Cotter. 1994. RasG protein accumulation occurs just prior to amoebae emergence during spore germination in Dictyostelium discoideum. FEMS Microbiol. Lett. 117: 293298.

Khosla, M., G.B. Spiegelman, and G. Weeks. 1996. Overexpression of an activated rasG gene during growth blocks the initiation of Dictyostelium development. Mol. Cell. Biol. 16: 4156-4162.

Louis, S.A., G.B. Spiegelman, and G. Weeks. 1997. Expression of an activated rasD gene changes cell fate decisions during Dictyostelium development. Mol. Biol. Cell 8: 303-312.

Mulcahy, L.S., M.R. Smith, and D.W. Stacey. 1985. Requirement for ras proto-oncogene function during serum-stimulated growth of NIH 3T3 cells. Nature 313: 241-243.

Reymond, C.D., R.H. Gomer, M.C. Mehdy, and R.A. Firtel. 1984. Developmental regulation of a Dictyostelium gene encoding a protein homologous to mammalian Ras protein. Cell 39: 141-148.

Reymond, C.D., R.H. Gomer, W. Nellen, A. Theibert, P. Devreotes, and R. Firtel. 1986. Phenotypic changes induced by a mutated Ras gene during the development of Dictyostelium transformants. Nature 323: 340-343.

Robbins, S.M., J.G. Williams, K.A. Jermyn, G.B. Spiegelman, and G. Weeks. 1989. Growing and developing Dictyostelium cells express different ras genes. Proc. Natl. Acad. Sci. 86: $938-942$.

Shih, T., M. Weeks, H. Young, and E. Scolnick. 1979. Identification of a sarcoma virus-coded phosphoprotein in nonproducer cells transformed by Kirsten or Harvey murine sarcoma virus. Virology 96: 64-79.

Smith, E., P.R. Fisher, W.N. Grant, and K.L. Williams. 1982. Sensory behaviour in Dictyostelium discoideum slugs: Phototaxis and thermotaxis are not mediated by a change in slug speed. J. Cell Sci. 54: 329-339.

Sorcher, S., A. Schonthal, A. Alberts, J. Meinkoth, and J. Feramisco. 1993. The ras superfamily of GTPases. In The ras superfamily of GTPases (ed. J. Lacal and F. McCormick), pp. 85-101. CRC Press, Boca Raton, FL.

Sun, T.J., P.J.M. Van Haastert, and P.N. Devreotes. 1990. Surface cAMP receptors mediate multiple responses during development in Dictyostelium-evidenced by antisense mutagenesis. J. Cell Biol. 110: 1549-1554.

Sussman, R. and M. Sussman. 1967. Cultivation of Dictyostelium discoideum in axenic culture. Biochem. Biophys. Res. Commun. 29: 53-55.

Sutoh, K. 1993. A transformation vector for Dictyostelium discoideum with a new selectable marker Bsr. Plasmid 30: 150154.

Toda, T., I. Uno, T. Ishikawa, S. Powers, T. Kataoka, D. Broek, S. Cameron, J. Broach, K. Matsumoto, and M. Wigler. 1985. In yeast, RAS proteins are controlling elements of adenylate cyclase. Cell 40: 27-36.

Tuxworth, R.I., J.L. Cheetham, L.M. Machesky, G.B. Spiegelmann, G. Weeks, and R.H. Insall. 1997. Dictyostelium RasG is required for normal motility and cytokinesis, but not growth. J. Cell Biol. 138: 605-614.

Valencia, A. and C. Sander. 1995. The ras superfamily. In Guidebook to the small GTPases (ed. M. Zerial and L. Huber), pp. 12-19. Oxford University Press, Oxford, UK.

Van Haastert, P.J.M., F. Kesbeke, C.D. Reymond, R. Firtel, E. Luderus, and R. Van Driel. 1987. Aberrant transmembrane signal transduction in Dictyostelium cells expressing a mutated ras gene. Proc. Natl. Acad. Sci. 84: 4905-4909. 


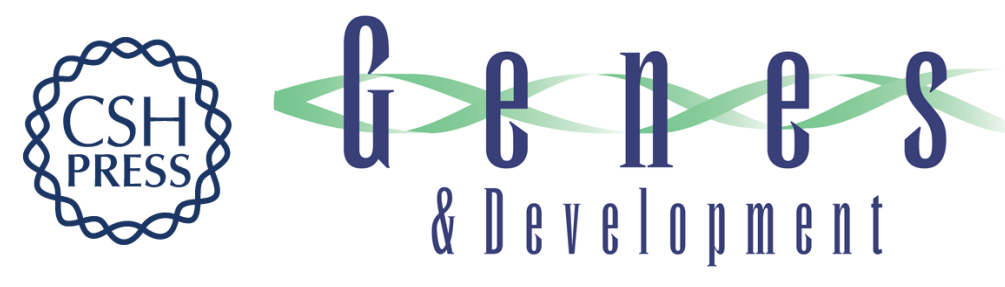

\section{Dictyostelium RasD is required for normal phototaxis, but not differentiation}

Andrew Wilkins, Meenal Khosla, Derek J. Fraser, et al.

Genes Dev. 2000, 14:

Access the most recent version at doi:10.1101/gad.14.11.1407

References

This article cites 36 articles, 15 of which can be accessed free at: http://genesdev.cshlp.org/content/14/11/1407.full.html\#ref-list-1

\section{License}

Email Alerting

Receive free email alerts when new articles cite this article - sign up in the box at the top Service right corner of the article or click here.

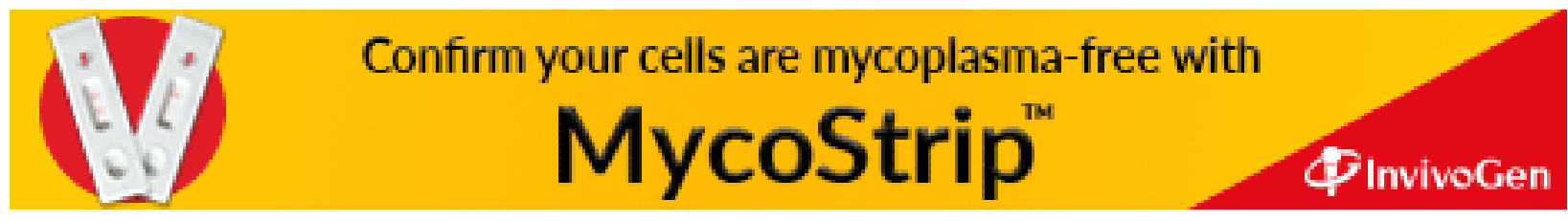

